\title{
Evaluation of black soldier fly larvae oil as a dietary fat source in broiler chicken diets
}

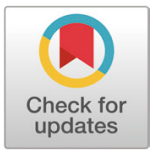

Received: Nov 26, 2019

Revised: Jan 3, 2020

Accepted: Feb 17, 2020

*Corresponding author

Sang Yun Ji

National Institute of Animal Science,

Rural Development Administration,

Wanju 55365, Korea.

Tel: +82-63-238-7455

E-mail: syjee@korea.kr

Copyright $(\subset) 2020$ Korean Society of Animal Sciences and Technology.

This is an Open Access article distributed under the terms of the Creative Commons Attribution

Non-Commercial License (http:// creativecommons.org/licenses/by$\mathrm{nc} / 4.0 /$ ) which permits unrestricted non-commercial use, distribution, and reproduction in any medium, provided the original work is properly cited.

ORCID

Byeonghyeon Kim

https://orcid.org/0000-0003-4651-6857

Han Tae Bang

https://orcid.org/0000-0003-0441-3542

Ki Hyun Kim

https://orcid.org/0000-0002-9834-2126

Min Ji Kim

https://orcid.org/0000-0003-2106-1921

Jin Young Jeong

https://orcid.org/0000-0002-8670-7036

Ju Lan Chun

https://orcid.org/0000-0002-4618-586X

Sang Yun Ji

https://orcid.org/0000-0001-7235-3655

Competing interests

No potential conflict of interest relevant to this article was reported.

Funding sources

This study was carried out with the support of "Cooperative Research

Program for Agriculture Science
Byeonghyeon Kim, Han Tae Bang, Ki Hyun Kim, Min Ji Kim, Jin Young Jeong, Ju Lan Chun and Sang Yun Ji*

National Institute of Animal Science, Rural Development Administration, Wanju 55365, Korea

\section{Abstract}

The present study was conducted to evaluate the effects of black soldier fly larvae oil (BSFLO) from the black soldier fly larvae (BSFL) as a partial or total replacement of soybean oil (SBO) on growth performance, fatty acid (FA) profile, and meat quality of broiler chickens from 1 to 5 wk of age. A total of 210 male broiler chickens (Ross 308 ) at one-day of age were randomly allotted to 3 dietary treatments (10 replicates and 7 birds/group): a basal control diet (CON), the basal diet in which the SBO was replaced by $50 \%$ (50 BSFLO) or $100 \%$ (100 BSFLO) of BSFLO. The growth performance, physical measurements and chemical traits of leg meat, and sensory analysis of breast meat were not influenced by diets. However, the relative weight $(\mathrm{g} / \mathrm{kg})$ of gizzard of CON was significantly higher $(14.85,12.52$, and 13.02 for CON, 50 BSFLO, and 100 BSFLO; $p<0.05$ ) than that of other treatments. As expected, the FA profile of breast meat was affected by BSFLO inclusion. The proportion (\%) of saturated fatty acid (SFA) was increased $(27.16,27.58$, and 28.72 for CON, 50 BSFLO, and 100 BSFLO; $p<0.05$ ) by BSFLO inclusion and the percentage (\%) of MUFA was also increased $(43.36,44.58$, and 48.55 for CON, 50 BSFLO, and 100 BSFLO; $p<0.01$ ). On the contrary, the proportion (\%) of PUFA was decreased (29.49, 27.84, and 22.74 for CON, 50 BSFLO, and 100 BSFLO; $p<$ 0.01 ). In conclusion, the present study suggests that the replacement of BSFLO did not show an adverse effect on growth performance and it could be an ingredient as a dietary fat source for a broiler diet.

Keywords: Black soldier fly larvae oil, Growth performance, Fatty acid profile, Meat quality

\section{INTRODUCTION}

Soybean oil (SBO) is the main dietary fat source for poultry diets because of its high energy content and digestibility [1]. However, the limited supply and the high price of the soybean are the critical aspects of poultry feed. The evaluation of the alternative ingredient as a dietary fat source in the broiler diet is therefore required.

Among the insect species, the black soldier fly (BSF, Hermetia illucens) is a promising species because of its ability to dissolve organic matter such as spoiled feed and manure [2,3]. The BSF larvae (BSFL) consume organic waste and store protein and fat in their bodies to supply the nutrients for the pupal period and adult stage [3]. Moreover, the nutritional component of BSFL depends on what they 
and Technology Development (Project No. PJ01456002)" Rural Development Administration, Korea.

Acknowledgements

This study was supported by the 2019 RDA

Fellowship Program of the National Institute

of Animal Science, Rural Development

Administration, Korea.

Availability of data and material

Upon reasonable request, the datasets

of this study can be available from the

corresponding author.

Authors' contributions

Conceptualization: Bang HT, Ji SY.

Data curation: Kim B.

Formal analysis: Kim B, Kim KH.

Methodology: Kim KH, Kim MJ, Jeong JY, Chun JL.

Software: Kim B, Kim MJ.

Validation: Kim B, Jeong JY.

Investigation: Bang $\mathrm{HT}$, Ji SY.

Writing - original draft: Kim B, Bang HT.

Writing - review \& editing: Jeong JY, Chun JL, Ji SY.

Ethics approval and consent to participate This study was approved by IACUC of Rural Development Administration (No. NIAS2019-1710). were fed [4]. Although the contents of protein and fat in the larvae meal and oil can be modulated by their feed and defatting procedure, the BSFL contains $42 \%$ of protein and $35 \%$ fat and it has shown the possibility as a protein and fat source for poultry $[2,3,5]$.

The use of the BSFL meal (BSFLM) and oil in the broiler diet have been reported [6-8]. The inclusion of BSFLM in broiler chicken diets up to $100 \mathrm{~g} / \mathrm{kg}$ had no negative effects on growth performance and meat quality [8]. Furthermore, Dabbou et al. [9] also reported that low level (100 $\mathrm{g} / \mathrm{kg}$ ) inclusion of the BSFLM in a starter broiler diet may improve growth performance. It seems that low-level inclusion of BSFLM may be a more appropriate method as they showed a common result that increasing the level of BSFLM can cause a decrease in body weight $[8,9]$. However, the replacement of black soldier fly larvae oil (BSFLO) had no detrimental effects on growth performance, intestinal morphology, and health, even though the SBO in a diet was fully replaced [6,7]. All these studies suggested that the use of BSFLO in a broiler diet is suitable. Nevertheless, information about the inclusion of BSFLO in a broiler diet on the meat quality and fatty acid (FA) profile is scarce. For this reason, the objective of the present study was to evaluate the BSFLO on growth performance, meat quality, and FA profile of broiler chickens.

\section{MATERIALS AND METHODS}

\section{Birds and diets}

The present study was conducted in the poultry facility of the National Institute of Animal Science of Korea. A total of 210 male broiler chicks (Ross 308) at one day of age were randomly allotted to 3 dietary treatments (10 pens/treatment and 7 birds/pen). The poultry house was equipped with an automatic ventilation system. Each pen was equipped with a feeder and an automatic drinker. On day 21 , chicks were randomly allocated to individual cages with a feeder and drinker.

The study was performed to evaluate the effects of a partial or total replacement of SBO with BSFLO on broiler chickens using two levels of inclusion. The diets were a control diet based on corn and soybean meal (SBM) and 50 and 100\% replacement of SBO with BSFLO. The diets were fed in three phases: starter (day 1 to 7), grower (day 7 to 21), and finisher (day 21 to 35). All diets were formulated to meet or exceed the NRC [10] requirements (Table 1). Feed and water were provided ad libitum throughout the trial.

\section{Growth performances}

Health status and mortality were recorded daily during the whole experimental period. The initial body weight (IBW) and the final body weight (FBW) were recorded on days 1 and 35. Daily feed intake (DFI), average daily gain (ADG), and feed conversion ratio (FCR) were determined for the overall experimental period (1 to 35 days).

\section{Slaughtering procedure}

Birds were grown to the age of 35 days and then slaughtered. Before slaughter, 33 birds (11 birds/ treatment) were chosen on the basis of average final live weight. Head, neck, and feet were removed and the length and weight of three sections of the small intestine were measured. The weight of the gizzard, liver, pancreas, spleen, bursa of Fabricius were also immediately weighed and recorded. A total of 33 chicken leg and breast meat samples were individually vacuum sealed and chilled at $4{ }^{\circ} \mathrm{C}$ to analyze physical measurements, chemical traits, oxidative parameters, and FA profile.

\section{Physical measurements and chemical traits of chicken leg meat}

Each $5 \mathrm{~g}$ of chicken leg meat samples (6 replicates) was homogenized with $15 \mathrm{~mL}$ distilled water 
Table 1. Ingredients and chemical composition of the experimental diets

\begin{tabular}{|c|c|c|c|c|c|c|c|c|c|}
\hline \multirow{2}{*}{ Items } & \multicolumn{3}{|c|}{ Starter } & \multicolumn{3}{|c|}{ Grower } & \multicolumn{3}{|c|}{ Finisher } \\
\hline & CON & 50 BSFLO & 100 BSFLO & CON & 50 BSFLO & 100 BSFLO & CON & 50 BSFLO & 100 BSFLO \\
\hline \multicolumn{10}{|l|}{ Ingredients (\%) } \\
\hline Corn & 53.05 & 53.05 & 53.05 & 59.00 & 59.00 & 59.00 & 61.80 & 61.80 & 61.80 \\
\hline Soybean meal (44\%) & 30.00 & 30.00 & 30.00 & 30.00 & 30.00 & 30.00 & 30.00 & 30.00 & 30.00 \\
\hline Corn gluten meal & 6.35 & 6.35 & 6.35 & 4.00 & 4.00 & 4.00 & 1.60 & 1.60 & 1.60 \\
\hline Wheat bran & 3.15 & 3.15 & 3.15 & - & - & - & - & - & - \\
\hline Soybean oil & 3.00 & 1.50 & - & 3.00 & 1.50 & - & 3.00 & 1.50 & - \\
\hline Black soldier fly larvae oil & - & 1.50 & 3.00 & - & 1.50 & 3.00 & - & 1.50 & 3.00 \\
\hline Dicalcium phosphate & 1.75 & 1.75 & 1.75 & 1.50 & 1.50 & 1.50 & 1.45 & 1.45 & 1.45 \\
\hline Limestone & 1.25 & 1.25 & 1.25 & 1.15 & 1.15 & 1.15 & 1.05 & 1.05 & 1.05 \\
\hline Vitamin-mineral premix ${ }^{1)}$ & 0.50 & 0.50 & 0.50 & 0.50 & 0.50 & 0.50 & 0.50 & 0.50 & 0.50 \\
\hline L-Lysine & 0.40 & 0.40 & 0.40 & 0.25 & 0.25 & 0.25 & 0.10 & 0.10 & 0.10 \\
\hline DL-Methionine & 0.20 & 0.20 & 0.20 & 0.20 & 0.20 & 0.20 & 0.15 & 0.15 & 0.15 \\
\hline Salt & 0.35 & 0.35 & 0.35 & 0.40 & 0.40 & 0.40 & 0.35 & 0.35 & 0.35 \\
\hline \multicolumn{10}{|l|}{ Calculated composition } \\
\hline $\mathrm{ME}(\mathrm{kcal} / \mathrm{kg})$ & 3,031 & 3,031 & 3,031 & 3,106 & 3,106 & 3,106 & 3,152 & 3,152 & 3,152 \\
\hline Lysine (\%) & 1.42 & 1.42 & 1.42 & 1.26 & 1.26 & 1.26 & 1.11 & 1.11 & 1.11 \\
\hline Methionine (\%) & 0.53 & 0.53 & 0.53 & 0.50 & 0.50 & 0.50 & 0.43 & 0.43 & 0.43 \\
\hline $\mathrm{Ca}(\%)$ & 0.96 & 0.96 & 0.96 & 0.91 & 0.91 & 0.91 & 0.86 & 0.86 & 0.86 \\
\hline Total P (\%) & 0.77 & 0.77 & 0.77 & 0.70 & 0.70 & 0.70 & 0.65 & 0.65 & 0.65 \\
\hline Available P (\%) & 0.46 & 0.46 & 0.46 & 0.41 & 0.41 & 0.41 & 0.36 & 0.36 & 0.36 \\
\hline \multicolumn{10}{|l|}{ Analyzed composition } \\
\hline Crude protein (\%) & 24.63 & 24.48 & 23.28 & 22.15 & 22.77 & 23.14 & 22.71 & 22.03 & 21.37 \\
\hline Crude fat (\%) & 3.63 & 5.39 & 5.93 & 6.76 & 7.51 & 7.70 & 4.68 & 4.44 & 5.22 \\
\hline NDF (\%) & 8.95 & 10.51 & 10.27 & 11.00 & 12.49 & 14.43 & 11.83 & 16.39 & 12.55 \\
\hline ADF (\%) & 3.93 & 4.17 & 3.78 & 3.88 & 3.56 & 3.45 & 4.13 & 4.24 & 3.33 \\
\hline Ash (\%) & 8.22 & 7.60 & 7.06 & 7.67 & 7.13 & 7.24 & 7.78 & 7.16 & 7.89 \\
\hline
\end{tabular}

${ }^{1)}$ Supplied per kilogram of diet: vitamin A 1,600,000 IU; vitamin $D_{3} 300,000 \mathrm{IU}$; vitamin E $800 \mathrm{IU}$; vitamin $\mathrm{K}_{3} 132 \mathrm{mg}$; vitamin $\mathrm{B}_{1} 97 \mathrm{mg}$; vitamin $\mathrm{B}_{2} 500 \mathrm{mg}$; vitamin $\mathrm{B}_{6} 200 \mathrm{mg}$; vitamin $\mathrm{B}_{12} 1.2 \mathrm{mg}$; nicotinic acid 2,000 mg; pantothenic acid $800 \mathrm{mg}$; folic acid $60 \mathrm{mg}$; choline chloride 35,000 mg; Mn 12,000 mg; Zn 9,000 mg; Fe 4,000 mg; Cu 500 mg; I 250 mg; Co $100 \mathrm{mg}$; Se $50 \mathrm{mg}$.

CON, control diet; 50 BSFLO, 50\% black soldier fly larvae oil diet; 100 BSFLO, 100\% black soldier fly larvae oil diet; ME, metabolizable energy.

and then homogenized with a homogenizer (T 25 digital ultra-turrax, IKA, Germany) at 10,000 ×g for $1 \mathrm{~min}$. The $\mathrm{pH}$ values of the homogenates were determined using a $\mathrm{pH}$ meter (AM-7, Nihonseiki Kaisha, Tokyo, Japan). All determinations were performed in triplicate.

The leg meat samples were cooked in a polyethylene plastic bag and heated in a water bath operating at $80^{\circ} \mathrm{C}$ to an internal temperature of $75^{\circ} \mathrm{C}$. After cooking and cooling, the samples were dried and weight to calculate the cooking loss (\%). The samples were cut into $1.5 \times 1.5 \mathrm{~cm}$ sized pieces. Shear force analysis was performed using a TA-HDi Texture Analyzer (Stable Macro System, London, UK). Each block was sheared at a constant speed of $1 \mathrm{~mm} / \mathrm{s}$. The water holding capacity (WHC) was measured followed by the guide of Kauffman et al. [11]. The Samples were also analyzed for moisture, crude protein (CP), ether extract (EE), and ash [12].

Thiobarbituric acid-reactive substances (TBARS) and volatile basic nitrogen (VBN) The thiobarbituric acid-reactive substances (TBARS) and volatile basic nitrogen (VBN) were also measured on $\mathrm{d}$ 0,3, and 6 during the storage period as described by Witte et al. [13]. On each day, 
$10 \mathrm{~g}$ minced leg meat samples (5 replicates) were homogenized with $10 \mathrm{~mL}$ of trichloroacetic acid, and the sample volume was adjusted to $50 \mathrm{~mL}$ by adding distilled water. The homogenization was performed at 10,000 $\times g$ for 5 min with a homogenizer (T 25 digital ultra-turrax, IKA, Germany). After centrifugation, the supernatant was filtered using a filter paper (Whatman No. 1) and $5 \mathrm{~mL}$ of the supernatant was added to $5 \mathrm{~mL}$ of 2-thiobarbituric acid $(0.005 \mathrm{mM})$. The samples were then mixed and the mixture was heated. Next, the absorbance was measured at $532 \mathrm{~nm}$ using a UV/VIS spectrophotometer (OPTI-ZEN 2120UV, Mecasys, Daejeon, Korea). The result was expressed as mg malonaldehyde (MDA) equivalents/kg sample.

The VBN was analyzed according to Conway [14]. The $10 \mathrm{~g}$ of leg meat samples (5 replicates) was homogenized for $10 \mathrm{~min}$ with $90 \mathrm{~mL}$ of distilled water using homogenizer (T 25 digital ultra-turrax, IKA, Germany). The homogenate was centrifuged for $10 \mathrm{~min}$ at $800 \times \mathrm{g}$, and the supernatant was filtered using a filter paper (Whatman No. 1). Next, $1 \mathrm{~mL}$ of $0.01 \mathrm{~N}$ boric acid as a VBN absorber was placed in the inner section of a Conway micro diffusion cell. And then, $1 \mathrm{~mL}$ of filtrate and $1 \mathrm{~mL}$ of $50 \%$ potassium carbonate were added to the outer section of the Conway micro diffusion cell. The cell was incubated at $37^{\circ} \mathrm{C}$ for $120 \mathrm{~min}$ and titrated with $0.02 \mathrm{~N}$ sulfuric acid. The blank test was conducted following the same process without adding $1 \mathrm{~mL}$ of $50 \%$ potassium carbonate.

\section{Fatty acid profile of black soldier fly larvae oil and chicken breast meat}

The lipid extraction was performed using chloroform:methanol (1:2) for breast meat samples (6 replicates). The samples were transmethylated using a methanolic solution of $\mathrm{H}_{2} \mathrm{SO}_{4}(4 \%)$ to determine fatty acid methyl esters (FAME). A biphasic separation was obtained by adding $0.5 \mathrm{~mL}$ of distilled water and $1.5 \mathrm{~mL}$ of $\mathrm{N}-\mathrm{Heptane}$ to each sample. The FAME was determined by gas chromatography (Agilent 7890A series, Agilent Technologies, Wilmington, DE, USA), equipped with a Hewlett Packard HP-88 capillary column (60 m length, $0.52 \mathrm{~mm}$ internal diameter, and $0.20 \mu \mathrm{m}$ film thickness; J\&W Scientific, USA) and a flame ionization detector. The carrier gas was helium and the detector temperature was $260^{\circ} \mathrm{C}$ with the split ration (30:1). The FAs were identified based on a standard FAME mixture (37-Component FAME Mix, Supelco, Bellefonte, PA, USA). The results were expressed as the percentage (\%) of total detected FAME (Table 2).

\section{Sensory analysis of chicken breast meat}

Sensory evaluation was conducted by a panel consisting of 6 assessors at the National Institute of Animal Science. For the experiment, a total of 5 breasts per treatment were used and 3 days of analysis were scheduled (day 0,3 , and 6 during the storage period). The breast meats were removed from the refrigerator on each sampling day and used directly. After that, each sample was heated at $80^{\circ} \mathrm{C}$ for $8 \mathrm{~min}$, until the core temperature reached $74^{\circ} \mathrm{C}$. The samples were put on aluminum trays and served to the assessors. The descriptors were color, flavor, juiciness, firmness, and overall preference and the intensity of the sensory attributes was scored from 1 to 9 , with 1 as low intensity and 9 as high intensity.

\section{Statistical analysis}

Data were analyzed using the PROC GLM of SAS (SAS Inst., Cary, NC, USA). The experimental unit was the pen for growth performance and the individual bird was used for slaughter traits, oxidative and meat quality parameters, and FA profile. Results are given as mean and standard error of the mean (SEM). Statistical significance and tendency were considered at $p<0.05$ and $0.05 \leq p$ $<0.10$, respectively. 
Table 2. Fatty acid profile (\% of total FAME) of the black soldier fly larvae oil (BSFLO)

\begin{tabular}{lcr}
\hline & Fatty acids & BSFLO \\
\hline C10:0 & 1.76 \\
C12:0 (Lauric) & 35.72 \\
C14:0 (Myristic) & 5.03 \\
C16:0 (Palmitic) & 13.78 \\
C17:0 & 0.20 \\
C18:0 (Stearic) & 2.81 \\
C16:1 & 2.12 \\
C17:1 & 0.18 \\
C18:1 n-9 (Oleic) & 18.28 \\
C22:2 & 0.18 \\
C18:2 n-6 (Linoleic) & 15.02 \\
C18:3 n-3 (Linolenic) & 1.95 \\
C18:4 n-3 & 0.54 \\
C20:3 n-3 & 0.32 \\
C20:5 n-3 (EPA) & 0.98 \\
\hline
\end{tabular}

FAME, fatty acid methyl esters.

\section{RESULTS AND DISCUSSION}

In the present study, partial or total replacement of SBO with BSFLO for broiler chickens has no detrimental effect on growth performance. The inclusion of 100\% BSFLO also did not lead to any negative effect on growth performance compared to 50\% BSFLO inclusion. This result shows the possibility of total replacement of SBO by BSFLO. The IBW was the same in all groups and the FBW also did not show differences among dietary treatment groups (Table 3). The DFI, ADG, and FCR were not affected by the inclusion of BSFLO (Table 3). The mortality was not affected by the inclusion of BSFLO (not shown). The previous researches were also reported that the inclusion of BSFLO in a broiler diet did not affect the growth performance [6,7]. Through these results, it is possible to replace $100 \%$ of the SBO with the BSFLO in the broiler diet in terms of growth performance.

Similarly to the result of growth performance, the replacement of BSFLO did not affect the organ yields except the relative weight of the gizzard. The previous studies also have shown no significant differences in carcass traits by the replacement of BSFLO [6,7]. However, the inclusion

Table 3. Effect of the dietary black soldier fly larvae oil inclusion level on the growth performance of the broiler chickens ${ }^{1)}$

\begin{tabular}{lrrrrr}
\hline & \multicolumn{3}{c}{ Dietary treatments } & \multirow{2}{*}{ SEM } & \multirow{2}{*}{$\boldsymbol{p}$-value } \\
\cline { 2 - 4 } & \multicolumn{1}{c}{ CON } & $\mathbf{5 0}$ BSFLO & $\mathbf{1 0 0}$ BSFLO & & \\
\hline IBW (g, d 1) & 41.60 & 41.71 & 41.20 & 0.16 & 0.104 \\
FBW (g, d 35) & $1,739.82$ & $1,730.88$ & $1,743.50$ & 43.92 & 0.978 \\
DFI (g) & 79.06 & 81.38 & 79.60 & 1.19 & 0.386 \\
ADG (g) & 49.71 & 49.45 & 49.81 & 1.25 & 0.978 \\
FCR (g/g) & 1.59 & 1.65 & 1.60 & 0.03 & 0.492 \\
\hline
\end{tabular}

${ }^{11}$ Each value is the mean of 10 replicates (7 birds/group).

CON, control diet; 50 BSFLO, 50\% black soldier fly larvae oil diet; 100 BSFLO, 100\% black soldier fly larvae oil diet; SEM, standard error of the mean; IBW, initial body weight; FBW, final body weight; DFI, daily feed intake; ADG, average daily gain; FCR, feed conversion ratio. 
(150 g/kg) of BSFLM for broiler chickens negatively affect the carcass weight [8]. Dabbou et al. [9] observed that the negative effects on growth performance and carcass trait by $15 \%$ inclusion level in the broiler diet were caused by reduced villus height:crypt depth. Interestingly, the relative gizzard weight was significantly higher $(p=0.028)$ in the control group than in other groups (Table 4$)$. A similar result was reported that the weight of gizzard in a control group was heavier than that of other treatments where BSFLM was included in a broiler chicken diet [15]. Moreover, they compared several kinds of BSFLM which are differently defatted in terms of organ yields. The relative weight of the gizzard of broilers fed full-fat BSFLM was lower than those fed extruded BSFLM. However, the replacement of fish meal with a maggot in a broiler diet, as opposed to BSFLM and BSFLO, increased the weight of gizzard [16]. Overall, it seems that the inclusion of the BSFL by-product may affect the weight of the gizzard and further studies are required to better understand the mechanism.

The results of the physical and chemical traits of chicken leg meat were satisfactory and suggested that the use of the BSFLO in the broiler diet as an alternative of SBO. The inclusion of BSFLM in terms of carcass weight and dressing percentage had no adverse effect on chicken meat quality [17]. They also investigated the $\mathrm{pH}$, color, and cooking loss of breast meat and the $\mathrm{pH}$ was decreased by the inclusion of BSFLM. The low $\mathrm{pH}$ value can cause a decrease of WHC and the increase of cooking loss when the value of $\mathrm{pH}$ is between 5.2 to 5.5 [17]. However, in the present study, the replacement of BSFLO did not show any adverse effects on the physical measurements of chicken leg meat in Table 5 and the $\mathrm{pH}$ value was in a normal range [18]. For this reason, the results of moisture, WHC, and cooking loss which are related to $\mathrm{pH}$ value had no significant differences among treatments. However, the more substitution level (24.8\% of SBM and 100\% of SBO) of BSFLM in a broiler diet increased the shear force and cooking loss compared to less substitution (16.1\% of SBM and $28.4 \%$ of SBO) of BSFLM [17]. It seems that the high inclusion level of BSFLM may

Table 4. Effects of the dietary black soldier fly larvae oil inclusion level on the relative length $(\mathrm{cm} / \mathrm{kg})$ of the different sections of the digestive tract, relative weight $(\mathrm{g} / \mathrm{kg})$ of the digestive track and internal organs of broiler chickens at $35 \mathrm{~d}$ of age ${ }^{1)}$

\begin{tabular}{|c|c|c|c|c|c|}
\hline \multirow{2}{*}{ Items } & \multicolumn{3}{|c|}{ Dietary treatments } & \multirow{2}{*}{ SEM } & \multirow{2}{*}{$p$-value } \\
\hline & CON & 50 BSFLO & 100 BSFLO & & \\
\hline LW (kg) & 1.99 & 1.98 & 2.08 & 0.04 & 0.229 \\
\hline \multicolumn{6}{|l|}{ Intestinal sections } \\
\hline Duodenum length $(\mathrm{cm} / \mathrm{kg})$ & 14.32 & 14.44 & 13.34 & 0.55 & 0.330 \\
\hline Jejunum length $(\mathrm{cm} / \mathrm{kg})$ & 33.17 & 30.50 & 32.69 & 0.90 & 0.107 \\
\hline lleum length (cm/kg) & 33.56 & 30.00 & 32.09 & 1.14 & 0.111 \\
\hline Duodenum weight $(\mathrm{g} / \mathrm{kg})$ & 6.63 & 6.26 & 6.27 & 0.30 & 0.628 \\
\hline Jejunum weight (g/kg) & 10.91 & 10.41 & 10.41 & 0.45 & 0.665 \\
\hline Ileum weight (g/kg) & 7.61 & 8.16 & 7.68 & 0.33 & 0.456 \\
\hline \multicolumn{6}{|l|}{ Internal organs } \\
\hline Gizzard (g/kg) & $14.85^{\mathrm{a}}$ & $12.52^{b}$ & $13.02^{b}$ & 0.59 & 0.028 \\
\hline Liver (g/kg) & 21.67 & 19.94 & 21.19 & 0.85 & 0.349 \\
\hline Pancreas (g/kg) & 2.28 & 2.20 & 2.31 & 0.13 & 0.849 \\
\hline Spleen $(\mathrm{g} / \mathrm{kg})$ & 1.14 & 0.95 & 1.09 & 0.08 & 0.271 \\
\hline Bursa of Fabricius ( $\mathrm{g} / \mathrm{kg}$ ) & 1.80 & 1.66 & 1.42 & 0.29 & 0.655 \\
\hline
\end{tabular}

${ }^{11}$ Each value is the mean of 11 replicates (11 birds/treatment).

a,b Means with different letters within each variable differ $(p<0.05)$.

CON, control diet; 50 BSFLO, 50\% black soldier fly larvae oil diet; 100 BSFLO, 100\% black soldier fly larvae oil diet; SEM, standard error of the mean; LW, live weight. 
Table 5. Physical measurements and chemical traits of chicken leg meat as affected by diets containing different levels of black soldier fly larvae oil (BSFLO) ${ }^{1)}$

\begin{tabular}{|c|c|c|c|c|c|}
\hline \multirow{2}{*}{ Parameters } & \multicolumn{3}{|c|}{ Treatments } & \multirow{2}{*}{ SEM } & \multirow{2}{*}{$p$-value } \\
\hline & CON & 50 BSFLO & 100 BSFLO & & \\
\hline $\mathrm{pH}$ & 5.82 & 5.82 & 5.86 & 0.04 & 0.802 \\
\hline Shear force $\left(\mathrm{kg} / 0.5 \mathrm{inch}^{2}\right)$ & 3.33 & 3.29 & 2.79 & 0.55 & 0.745 \\
\hline Cooking loss (\%) & 15.29 & 18.52 & 15.49 & 1.02 & 0.074 \\
\hline WHC (\%) & 61.66 & 61.14 & 59.64 & 0.77 & 0.196 \\
\hline Moisture (\%) & 75.47 & 76.11 & 75.83 & 0.38 & 0.516 \\
\hline Crude protein (\%) & 22.14 & 21.83 & 21.89 & 0.37 & 0.833 \\
\hline Ether extract (\%) & 1.36 & 1.18 & 1.17 & 0.19 & 0.754 \\
\hline Ash (\%) & 1.11 & 1.07 & 1.11 & 0.03 & 0.527 \\
\hline
\end{tabular}

${ }^{1)}$ Each value is the mean of 6 replicates (6 birds/treatment).

CON, control diet; 50 BSFLO, 50\% black soldier fly larvae oil diet; 100 BSFLO, 100\% black soldier fly larvae oil diet; SEM, standard error of the mean; WHC, water holding capacity.

affect the physical measurements of chicken breast meat. On the other hand, the total substitution of the BSFLO did not affect the shear force and cooking loss in the chicken leg meat compared to the partial substitution of the BSFLO in this study (Table 5). The chemical quality such as CP, $\mathrm{EE}$, and ash of chicken leg meat was also not affected by treatment (Table 5). Several studies have also shown the same results that the total replacement of the SBO with BSFLO did not affect the chemical quality of chicken meat $[6,8]$.

A major concern of using BSFLM and BSFLO is that the supplementation negatively affects the meat quality by a decrease of polyunsaturated fatty acid (PUFA), increase of saturated fatty acid (SFA) and monounsaturated fatty acid (MUFA) in the meat. The SFA is the main FA in BSF derived oil and lauric acid (C12:0), palmitic acid (C16:0), and oleic acid (C18:1) are predominant FAs [4]. Moreover, the BSFL contains a high level of lauric acid which has an antimicrobial effect on gut pathogens [19-21]. Even though the partial replacement of BSFLO has shown no negative effects on growth performance and gut health, the BSFLO has a defect that alters the FA profile of the meat [6-8]. As expected, in the present study, the replacement of the BSFLO altered the FA profile of the chicken breast meat (Table 6). The content of the SFA was increased (27.16\%, $27.58 \%$, and $28.72 \%$ in CON, 50 BSFLO, and $100 \mathrm{BSFLO}, p=0.011$ ) by the addition of the BSFLO. However, contrary to the result of the SFA, the unsaturated fatty acid (UFA) was decreased $(72.85 \%, 72.42 \%$, and $71.29 \%$ in CON, 50 BSFLO, and 100 BSFLO, $p=0.011)$ by the total replacement of the BSFLO and the UFA/SFA was also significantly decreased $(2.69,2.63$, and 2.48 in CON, 50 BSFLO, and $100 \mathrm{BSFLO}, p=0.013$ ). The reason for the change of the FA profile is that the high level of SFA in the BSFLO influences the fraction of PUFA [22]. Schiavone et al. [6] reported that the MUFA was not affected by the BSFLO. On the contrary, in the present study, the fraction of MUFA was increased (43.36\%, 44.58\%, and 48.55\% in CON, 50 BSFLO, and 100 BSFLO, $p<0.001$ ) and this result stems from the desaturation and elongation of SFA such as $\mathrm{C} 14: 0, \mathrm{C} 16: 0$, and C18:0. The inclusion of BSFLM in a broiler and laying quails also changed the FA profile in the breast meat and eggs [8,23]. They commonly reported that the concentration of SFA and MUFA was increased and PUFA was decreased. The one thing that should be improved is the negative change of the FA composition of meat when the BLSFM and BSFLO were included. Even though 100 BSFLO showed increased UFA/SFA, there was no significant difference between CON and 50 BSFLO (Table 6). This result means that it seems appropriate to replace with the BSFLO less than $50 \%$ in terms of the meat quality. 
Table 6. Fatty acid profile (\% of total FAME) of chicken breast meat as affected by diets containing different levels of black soldier fly larvae oil (BSFLO) ${ }^{1)}$

\begin{tabular}{lrrrrr}
\hline \multirow{2}{*}{ Parameters } & \multicolumn{3}{c}{ Treatments } & \multirow{2}{*}{ SEM } & p-value \\
\cline { 2 - 3 } & CON & 50 BSFLO & 100 BSFLO & & \\
\hline C14:0 (Myristic) & $0.55^{\mathrm{c}}$ & $1.07^{\mathrm{b}}$ & $1.74^{\mathrm{a}}$ & 0.08 & $<.001$ \\
C16:0 (Palmitic) & $20.35^{\mathrm{b}}$ & $21.06^{\mathrm{ab}}$ & $21.90^{\mathrm{a}}$ & 0.28 & 0.005 \\
C18:0 (Stearic) & $6.26^{\mathrm{a}}$ & $5.45^{\mathrm{b}}$ & $5.08^{\mathrm{b}}$ & 0.22 & 0.007 \\
SFA & $27.16^{\mathrm{b}}$ & $27.58^{\mathrm{b}}$ & $28.72^{\mathrm{a}}$ & 0.32 & 0.011 \\
C16:1 n-7 (Palmitoleic) & $3.82^{\mathrm{b}}$ & $3.59^{\mathrm{b}}$ & $4.78^{\mathrm{a}}$ & 0.23 & 0.006 \\
C18:1 n-9 (Oleic) & $39.13^{\mathrm{c}}$ & $40.61^{\mathrm{b}}$ & $43.32^{\mathrm{a}}$ & 0.45 & $<.001$ \\
C20:1 n-9 (Eicosenoic) & $0.41^{\mathrm{b}}$ & $0.38^{\mathrm{b}}$ & $0.45^{\mathrm{a}}$ & 0.01 & 0.003 \\
MUFA & $43.36^{\mathrm{b}}$ & $44.58^{\mathrm{b}}$ & $48.55^{\mathrm{a}}$ & 0.54 & $<.001$ \\
C18:2 n-6 (Linoleic) & $26.88^{\mathrm{a}}$ & $25.48^{\mathrm{a}}$ & $20.90^{\mathrm{b}}$ & 0.49 & $<.001$ \\
C18:3 n-6 (Y-Linolenic) & $0.24^{\mathrm{a}}$ & $0.19^{\mathrm{b}}$ & $0.17^{\mathrm{b}}$ & 0.01 & 0.005 \\
C18:3 n-3 (Linolenic) & $1.78^{\mathrm{a}}$ & $1.68^{\mathrm{a}}$ & $1.20^{\mathrm{b}}$ & 0.04 & $<.001$ \\
C20:4 n-6 (Arachidonic) & 0.59 & 0.49 & 0.47 & 0.04 & 0.176 \\
PUFA & $29.49^{\mathrm{a}}$ & $27.84^{\mathrm{b}}$ & $22.74^{\mathrm{c}}$ & 0.53 & $<.001$ \\
UFA & $72.85^{\mathrm{a}}$ & $72.42^{\mathrm{a}}$ & $71.29^{\mathrm{b}}$ & 0.32 & 0.011 \\
UFA/SFA & $2.69^{\mathrm{a}}$ & $2.63^{\mathrm{a}}$ & $2.48^{\mathrm{b}}$ & 0.04 & 0.013 \\
\hline
\end{tabular}

${ }^{1)}$ Each value is the mean of 6 replicates ( 6 birds/treatment).

${ }^{a-c}$ Means with different letters within each variable differ $(p<0.05)$.

FAME, fatty acid methyl esters; CON, control diet; 50 BSFLO, $50 \%$ black soldier fly larvae oil diet; 100 BSFLO, 100\% black soldier fly larvae oil diet; SEM, standard error of the mean; SFA, sum of saturated fatty acid; MUFA, sum of monounsaturated fatty acid; PUFA, sum of polyunsaturated fatty acid; UFA, sum of unsaturated fatty acid.

Table 7. Effects of the dietary black soldier fly larvae oil inclusion level on the thiobarbituric acidreactive substances (TBARS) and volatile basic nitrogen (VBN) of chicken leg meat ${ }^{1)}$

\begin{tabular}{|c|c|c|c|c|c|}
\hline \multirow{2}{*}{ Items } & \multicolumn{3}{|c|}{ Storage (d) } & \multirow{2}{*}{ SEM } & \multirow{2}{*}{$p$-value } \\
\hline & 0 & 3 & 6 & & \\
\hline \multicolumn{6}{|c|}{ TBARS (mg MDA/kg) } \\
\hline CON & $0.24^{b x}$ & $0.29^{b}$ & $0.48^{\mathrm{a}}$ & 0.03 & $<.001$ \\
\hline 50 BSFLO & $0.13^{\mathrm{cy}}$ & $0.35^{\mathrm{b}}$ & $0.54^{\mathrm{a}}$ & 0.04 & $<.001$ \\
\hline 100 BSFLO & $0.12^{\text {cy }}$ & $0.36^{\mathrm{b}}$ & $0.61^{a}$ & 0.04 & $<.001$ \\
\hline SEM & 0.01 & 0.02 & 0.06 & - & - \\
\hline$p$-value & $<.001$ & 0.058 & 0.434 & - & - \\
\hline \multicolumn{6}{|l|}{ VBN (mg \%) } \\
\hline CON & $9.53^{\mathrm{c}}$ & $10.18^{b}$ & $10.85^{\mathrm{a}}$ & 0.17 & $<.001$ \\
\hline 50 BSFLO & $9.33^{c}$ & $10.15^{\mathrm{b}}$ & $10.93^{\mathrm{a}}$ & 0.23 & 0.001 \\
\hline 100 BSFLO & $9.42^{\mathrm{b}}$ & $9.94^{b}$ & $10.86^{a}$ & 0.25 & 0.006 \\
\hline SEM & 0.14 & 0.28 & 0.22 & - & - \\
\hline$p$-value & 0.629 & 0.819 & 0.959 & - & - \\
\hline
\end{tabular}

${ }^{11}$ Each value is the mean of 5 replicates ( 5 birds/treatment).

${ }^{a-c}$ Different letters within same row differ significantly $(p<0.01)$.

${ }^{x, y}$ Different letters within same column differ significantly $(p<0.01)$.

SEM, standard error of the mean; CON, control diet; 50 BSFLO, $50 \%$ black soldier fly larvae oil diet; 100 BSFLO, 100\% black soldier fly larvae oil diet. 
The substitution of the BSFLO altered the oxidative status of the chicken leg meat resulting in a decrease of the TBARS value and this result seems to be affected by the decreased proportion of the PUFA. The TBARS and VBN values of all treatments were increased $(p<0.01)$ with longer storage periods (Table 7). However, the TBARS value of the control group was significantly higher $(p<$ 0.001) than in other groups on $d 0$ (Table 7). Even though the FA profile of the leg meat was only measured in the present study, the previous studies reported that the replacement of BSFLO in the broiler diet changed the FA profile of both breast meat and leg meat and the composition of SFA was also increased [6,22]. Although the high composition of the PUFA is more valuable for the chicken meat quality, the SFA is less vulnerable to lipid peroxidation than the USFA and TBARS inhibition of SFA was greater than that of USFA $[24,25]$. On the contrary to our result, Cullere et al. [22] observed that the result of TBARS did not show a significant difference by the inclusion of BSFLO in breast meat.

The sensory traits of the meat are an important point of view to evaluate the BSFLO and the sensory profiles of the breast meat derived from the chicken fed the BSFLO showed the meaningful result in the aspect of using the BSFLO as an alternative of the SBO. The breast meat of

Table 8. Effects of the dietary black soldier fly larvae oil inclusion level on the sensory evaluation of chicken breast meat ${ }^{1)}$

\begin{tabular}{|c|c|c|c|}
\hline \multirow{2}{*}{ Items } & \multicolumn{3}{|c|}{ Storage (d) } \\
\hline & 0 & 3 & 6 \\
\hline \multicolumn{4}{|l|}{ Color } \\
\hline CON & 4.77 & 4.22 & 4.44 \\
\hline 50 BSFLO & 4.33 & 4.22 & 4.72 \\
\hline 100 BSFLO & 4.44 & 4.27 & 4.22 \\
\hline SEM & 0.27 & 0.26 & 0.25 \\
\hline \multicolumn{4}{|l|}{ Flavor } \\
\hline CON & 4.88 & 4.27 & 4.44 \\
\hline 50 BSFLO & 4.83 & 4.66 & 4.50 \\
\hline 100 BSFLO & 4.88 & 4.38 & 4.50 \\
\hline SEM & 0.25 & 0.17 & 0.33 \\
\hline \multicolumn{4}{|l|}{ Juiciness } \\
\hline CON & 4.16 & 4.22 & 3.88 \\
\hline 50 BSFLO & 3.93 & 4.33 & 4.22 \\
\hline 100 BSFLO & 4.46 & 4.11 & 4.44 \\
\hline SEM & 0.18 & 0.15 & 0.17 \\
\hline \multicolumn{4}{|l|}{ Firmness } \\
\hline $\mathrm{CON}$ & 5.16 & 4.83 & 5.05 \\
\hline 50 BSFLO & 4.44 & 5.00 & 5.00 \\
\hline 100 BSFLO & 5.16 & 4.66 & 4.94 \\
\hline SEM & 0.26 & 0.46 & 0.46 \\
\hline \multicolumn{4}{|l|}{ Overall preference } \\
\hline CON & 5.00 & 4.69 & 4.44 \\
\hline 50 BSFLO & 4.44 & 4.63 & 4.50 \\
\hline 100 BSFLO & 5.11 & 4.44 & 4.61 \\
\hline SEM & 0.25 & 0.26 & 0.30 \\
\hline
\end{tabular}

${ }^{11}$ Each value is the mean of 5 replicates ( 5 birds/treatment).

CON, control diet; 50 BSFLO, 50\% black soldier fly larvae oil diet; 100 BSFLO, 100\% black soldier fly larvae oil diet; SEM, standard error of the mean. 
chickens fed the BSFLO showed similar sensory profiles compared to those fed CON (Table 8) The sensory traits of the chicken meat when the insect meal was included in a diet had also no detrimental effect on sensory analysis of eggs from layers fed BSFLM and of fish fed insect meal [5,22].

In conclusion, the present study showed that the partial or total replacement of SBO in the broiler chicken diets by the BSFLO showed comparable results on growth performance, meat quality, and sensory properties to the CON and the BSFLO could be a promising substitute as a dietary fat source in the broiler diet. However, further researches are necessary to improve the drawback that lowering the proportion of the PUFA by improving the FA profiles in the BSFLO as modulating their feed and defatting procedure.

\section{REFERENCES}

1. Dei HK. Soybean as a feed ingredient for livestock and poultry. In: Krezhova D, editor. Recent trends enhancing diversity quality of soybean products. Rijeka: IntechOpen; 2011.

2. Sheppard DC, Newton GL, Thompson SA, Savage S. A value added manure management system using the black soldier fly. Bioresour Technol. 1994;50:275-9.

3. Newton L, Sheppard C, Watson DW, Burtle G, Dove R. Using the black soldier fly, Hermetia illucens, as a value-added tool for the management of swine manure. Raleigh, NC: North Carolina State University; 2005. p. 1-17.

4. Surendra KC, Olivier R, Tomberlin JK, Jha R, Khanal SK. Bioconversion of organic wastes into biodiesel and animal feed via insect farming. Renew Energy. 2016;98:197-202.

5. Lock ER, Arsiwalla T, Waagbø R. Insect larvae meal as an alternative source of nutrients in the diet of Atlantic salmon (Salmo salar) postsmolt. Aquac Nutr. 2016;22:1202-13.

6. Schiavone A, Cullere M, De Marco M, Meneguz M, Biasato I, Bergagna S, et al. Partial or total replacement of soybean oil by black soldier fly larvae (Hermetia illucens L.) fat in broiler diets: effect on growth performances, feed-choice, blood traits, carcass characteristics and meat quality. Ital J Anim Sci. 2017;16:93-100.

7. Schiavone A, Dabbou S, De Marco M, Cullere M, Biasato I, Biasibetti E, et al. Black soldier fly larva fat inclusion in finisher broiler chicken diet as an alternative fat source. Animal. 2018;12:2032-39.

8. Schiavone A, Dabbou S, Petracci M, Zampiga M, Sirri F, Biasato I, et al. Black soldier fly defatted meal as a dietary protein source for broiler chickens: effects on carcass traits, breast meat quality and safety. Animal. 2019;13:2397-405.

9. Dabbou S, Gai F, Biasato I, Capucchio MT, Biasibetti E, Dezzutto D, et al. Black soldier fly defatted meal as a dietary protein source for broiler chickens: effects on growth performance, blood traits, gut morphology and histological features.J Anim Sci Biotechnol. 2018;9:49.

10. NRC [National Research Council]. Nutrient requirements of poultry. 9th ed. Washington, DC: National Academies Press; 1994.

11. Kauffman RG, Eikelenboom G, van der Wal PG, Engel B, Zaar M. A comparison of methods to estimate water-holding capacity in post-rigor porcine muscle. Meat Sci. 1986;18:307-22.

12. AOAC [Association of Official Analytical Chemists] International. Official methods of analysis of AOAC International. 16th ed. Arlington, VA: AOAC International; 1995.

13. Witte VC, Krause GF, Bailey ME. A new extraction method for determining 2-thiobarbituric acid values of pork and beef during storage.J Food Sci. 1970;35:582-5.

14. Conway EJ. Microdiffusion analysis and volumetric error. 3rd ed. London: Crosby Lockwood and Son; 1950.

15. Calderon A, Coles S, Davis D, Lanier J, Oliveira A. How to hear the shape of a billiard table 
[Internet]. 2018. http://arxiv.org/abs/1806.09644. Accessed 27 Dec 2019.

16. Okah U, Onwujiariri EB. Performance of finisher broiler chickens fed maggot meal as a replacement for fish meal.J Agric Technol. 2012;8:471-7.

17. Cullere M, Tasoniero G, Giaccone V, Miotti-Scapin R, Claeys E, De Smet S, et al. Black soldier fly as dietary protein source for broiler quails: apparent digestibility, excreta microbial load, feed choice, performance, carcass and meat traits. Animal. 2016;10:1923-30.

18. Tavaniello S, Maiorano G, Siwek M, Knaga S, Witkowski A, Di Memmo D, et al. Growth performance, meat quality traits, and genetic mapping of quantitative trait loci in 3 generations of Japanese quail populations (Coturnix japonica). Poult Sci. 2014;93:2129-40.

19. Zeitz JO, Fennhoff J, Kluge H, Stangl GI, Eder K. Effects of dietary fats rich in lauric and myristic acid on performance, intestinal morphology, gut microbes, and meat quality in broilers. Poult Sci. 2015;94:2404-13.

20. Kim SA, Rhee MS. Highly enhanced bactericidal effects of medium chain fatty acids (caprylic, capric, and lauric acid) combined with edible plant essential oils (carvacrol, eugenol, $\beta$-resorcylic acid, trans-cinnamaldehyde, thymol, and vanillin) against Escherichia coli O157: H7. Food Control. 2016;60:447-54.

21. Belghit I, Waagbø R, Lock EJ, Liland NS. Insect-based diets high in lauric acid reduce liver lipids in freshwater Atlantic salmon. Aquac Nutr. 2019;25:343-57.

22. Cullere M, Schiavone A, Dabbou S, Gasco L, Zotte AD. Meat quality and sensory traits of finisher broiler chickens fed with black soldier fly (Hermetia illucens L.) larvae fat as alternative fat source. Animals. 2019;9:140.

23. Zotte AD, Singh Y, Michiels J, Cullere M. Black soldier fly (Hermetia illucens) as dietary source for laying quails: live performance, and egg physico-chemical quality, sensory profile and storage stability. Animals. 2019;9:115.

24. Rael LT, Thomas GW, Craun ML, Curtis CG, Bar-Or R, Bar-Or D. Lipid peroxidation and the thiobarbituric acid assay: standardization of the assay when using saturated and unsaturated fatty acids. J Biochem Mol Biol. 2004;37:749-52.

25. Øverland M, Borge GI, Vogt G, Schøyen HF, Skrede A. Oxidative stability and sensory quality of meat from broiler chickens fed a bacterial meal produced on natural gas. Poult Sci. 2011;90:201-10. 